Egyptian

Orthodontic Journal

\title{
ESTABLISHMENT OF ARCH FORMS FOR UPPER EGYPT POPULATION
}

\author{
A. Labib*, W. Refai ${ }^{* *} \&$ B. Esawy ${ }^{* * *}$
}

ABSTRACT:

Objectives: Establishment of upper and lower arch forms for subjects from pure races in $V_{\text {pper Egypt. }}$

Material: 400 adolescent males with full permanent sets and having accepted normal occlusion were selected for this study.

Methods: upper \& Lower models were prepared, scanning and digitization were carried out using tracer version 2.1.39 Nile Delta company soft ware designed for this study. Five independent ratios were calculated for each upper and lower arch in order to characterize the different arch forms. Means clustering method was used for classification of the arch forms.

Results: For maxillary arch 3 arch forms were distinguished; wide, pointed and square. The same forms represented the mandibular arch. For maxillary arch; wide and pointed arch forms showed higher percentages than square arch form. In the mandibular arch; wide arch forms showed the highest percentages.

\section{INTRODUCTION}

The dental arches are defined as the composite structure of the dentition and the alveolar ridge. They show many developmental changes in size, shape and relationship from birth to the completion of permanent dentition.

Bolton ${ }^{(5)}$ established the discrepancies between mandibular and maxillary tooth material. It was found that an overall ratio of $91.3 \%$ and anterior ratio of $72.2 \%$ were necessary for proper coordination of the maxillary and mandibular teeth. Richardson and Malhotra ${ }^{(21)}$ measured 
the mesiodistal width of the teeth of 126 Negroes of equally divided sexes. Age was not included in the study. It was found that teeth of males were larger than those of females for each tooth in both arches.

Arch descriptions were studied longitudinally from 3 to 19 years of age. ${ }^{(22)}$ It was found that dimensions were larger for blacks than whites at all ages. In addition, the shape of the arches was less tapered in blacks. Peck \& Peck ${ }^{(20)}$ examined the relation between the crown shape (mesiodistal width divided by labiolingual width) and incisor alignment. It was concluded that tooth shape is a determining factor in the presence or absence of lower incisor crowding. The naturally well aligned mandibular incisors were smaller mesiodistally and larger labiolingually.

In an attempt to explore how many millimeters of tooth size discrepancy are clinically significant, 150 pretreatment study casts were selected. The results revealed that $2 \mathrm{~mm}$ of required tooth size correction was an appropriate threshold of clinical significance. ${ }^{(19)}$ The correlation between anterior tooth size discrepancies and Angle's classes and their prevalence in Brazilian population was investigated. ${ }^{(4)}$ Individuals with Class I and III malocclusions showed greater prevalence. Moreover, mean anterior tooth size discrepancy for Angle Class III subjects was significantly grater than for Class I and II subjects.

In Egypt, many studies were performed to analyze arch dimensions and mesiodistal teeth width. El Mangoury ${ }^{(8)}$ concluded that mandibular intercanine width tended to relapse to its original value. Eid ${ }^{(9)}$ applied Bolton and Peck and Peck analyses on a sample of 143 Egyptian subjects. The significant difference found between Egyptian and American ratios

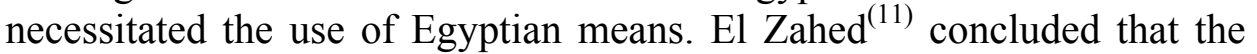
teeth size of males was slightly larger than that of females. In addition, the teeth size of Egyptians was slightly smaller than that of American Negroes. Some studies also indicated a significant sex difference in almost all teeth being higher in males. ${ }^{(1)}$

Nassef and Attia ${ }^{(18)}$ evaluated the best fit commercially available customized memory arch wires for the Egyptian adults. They recommended the use of commercially available lower arch wires for the maxillary arch and use the best fit available arch wire in the market for the lower arch. 
Egyptian

Orthodontic Journal

Concerning Upper Egypt, the maxillary arch length showed a mean value of $8.38 \mathrm{~mm}$ for the anterior arch length, $28.1 \mathrm{~mm}$ for the posterior arch length and $34.89 \mathrm{~mm}$ for the total arch length. The mandibular arch length showed a mean value of $4.78 \mathrm{~mm}$ for the anterior arch length, $33.72 \mathrm{~mm}$ for the posterior arch length and $34.89 \mathrm{~mm}$ for the total arch length. ${ }^{(12)}$

Concerning regional researches, many studies were carried out. Kaddah and Ramadan ${ }^{(15)}$ conducted a study to establish normative data of mesiodistal crown dimension in a sample of Yemeni adolescents. The results indicated that the mesiodistal width of maxillary lateral incisor, second premolar and mandibular first premolar were significantly smaller than those of the corresponding measurements. The mean mesiodistal teeth width of Yemeni population was found to be smaller than that of Egyptian, Jordanian and Palestinian populations. ${ }^{(3)}$

It was also found that there were limitations of Tanaka and Johnston equations when predicting tooth size in Saudi Arab children. ${ }^{(2)}$ Moreover, it was concluded that Jordanians had tooth sizes close to those of Iraqis but significantly larger than those of Yemenite-Jews, Caucasians and Chinese. ${ }^{(14)}$ El Ajramy ${ }^{(15)}$ concluded that the mean mesiodistal widths of Palestinian population was similar to that of Egyptians, larger than Yemeni and larger than Jordanians

The plaster models permit three dimensional studies of dental arches for diagnosis and treatment planning. They also provide a reference throughout treatment. Moreover, computer-aided occlusogram can provide the basis of the computerized appliance design. ${ }^{(13)}$

The occlusogram permits the clinician to make highly accurate and reliable space analysis by superimposing the idealized arch form on the original one. In addition, it can be used to develop an ideal, natural, individualized arch form for each patient without time consuming or special devices. This can provide a template for arch wire construction throughout treatment.

The 3-D occlusogram technique and procedure was described. It includes four stages: image scanning and setting, occlusal view processing, 
lateral cephalometric processing, and occlusogram construction. By using this technique, alternative treatment approaches can be easily compared and discussed with the patient. In addition, the technique is more rapid and more precise than the manual method. ${ }^{(13)}$

Various cast studies were conducted using software and acclusogram. Yen ${ }^{(23)}$ conducted a study using computer program. It was suggested that a space analysis program could be integrated with a comprehensive diagnostic program. Borgan ${ }^{(6)}$ used special software program when establishing the standards of dental arch dimensions and forms among Jordanian. Mutinelli et $\mathrm{al}^{(17)}$ conducted a research to describe a computerized method which enabled to analyze variation of dental arch form and dimension.

Surveying the literature, many investigators found differences in tooth size and arch dimensions between various ethnic groups. Many studies had been performed in Egypt to analyze the dental arch regarding the changes that occurred during growth and development. However, information about the dental arch dimensions in general and arch form in particular among Upper Egypt population is still lacking which brought up the idea for this research.

\section{MATERIALS AND METHODS}

The study was performed on a sample of 400 Egyptian subjects with age ranging from 14 to 16 years. They were selected randomly from schools of Minia, Asuit, Sohag and Aswan Governorates (Upper Egypt).

All subjects had an accepted normal occlusion. Fully erupted maxillary and mandibular teeth, accepted overbite and overjet as well as absence of cross bite skeletal discrepancies and congenital anomalies were mandatory. 
Upper and lower models were taken with suitable size perforated trays with high flanges. Alginate was used to take the impression*. The impressions were immediately poured in hard dental stone ${ }^{* *}$.

Scanning and digitization (Fig 1,2) were carried out using tracer version 2.1.39 Nile Delta company software specially designed for this study. The following points were determined on the scanned image: the midpoint of the incisal edge of central and lateral incisors (1I and 2I), the cusp tips of the canines and premolars (3C, 4C and 5C) and the mesiobuccal and distobuccal cusps of the first and second permanent molars (6M BC, $6 \mathrm{DBC}, 7 \mathrm{MBC}$ and $7 \mathrm{DMC}$ ).

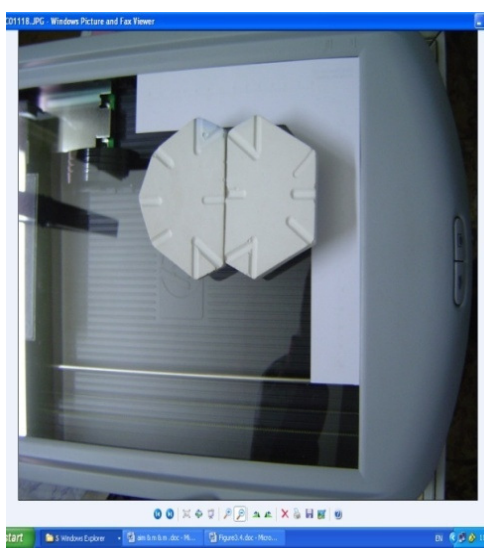

Fig1: Scanning process

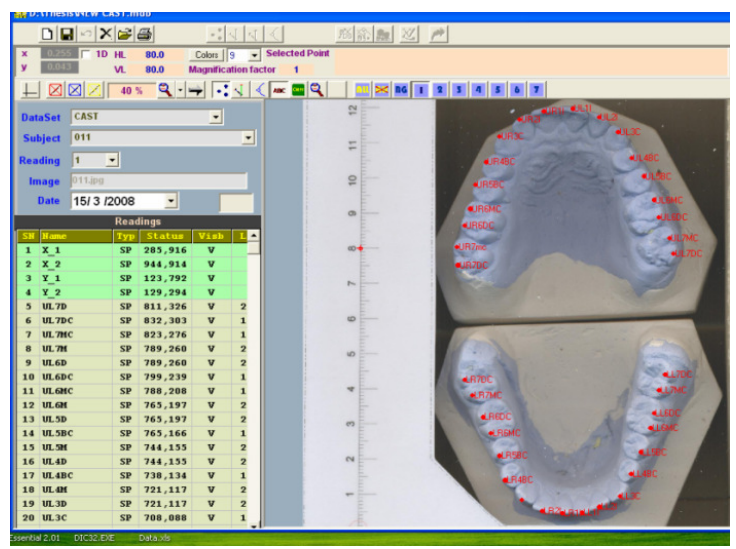

Fig 2: Digitization of the scanned image

Concerning measurements, the following was calculated:

\section{1- Anterior arch length:}

This was measured by calculating the inter-incisal point located at mid-point between between the proximal surfaces of the central incisors to the mid-distance of the inter-canine width. (Fig 3)

\section{2- Posterior arch length:}

This was calculated by the measuring the distance between the inter-incisal point to the mid-distance of inter-first molar width. (Fig 4)

\footnotetext{
* Tulip Alginate, Cavex, Holland

** Hard Dental Stone, Dentaurum Company, Germany
} 

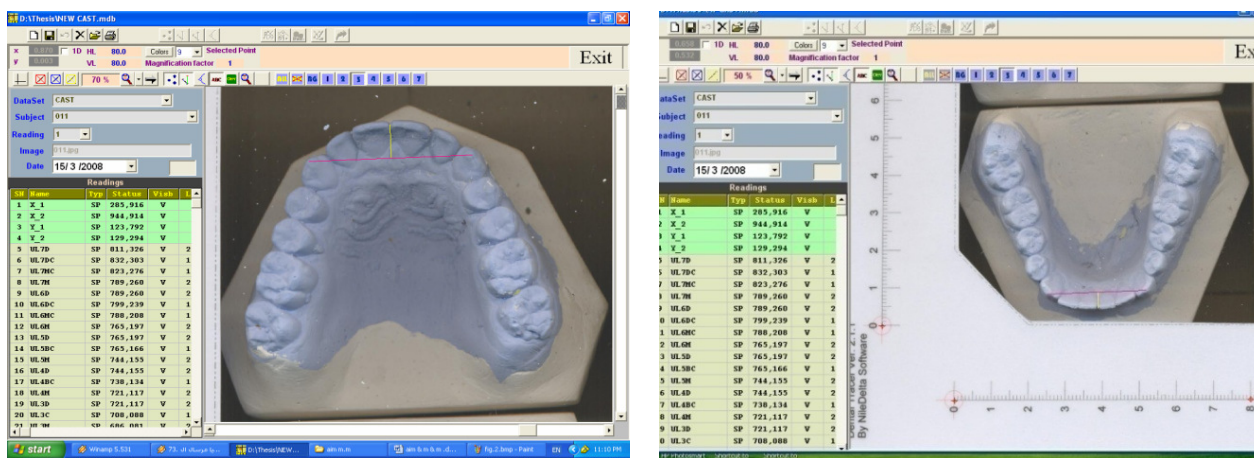

Fig 3: Maxillary and mandibular anterior arch lengths
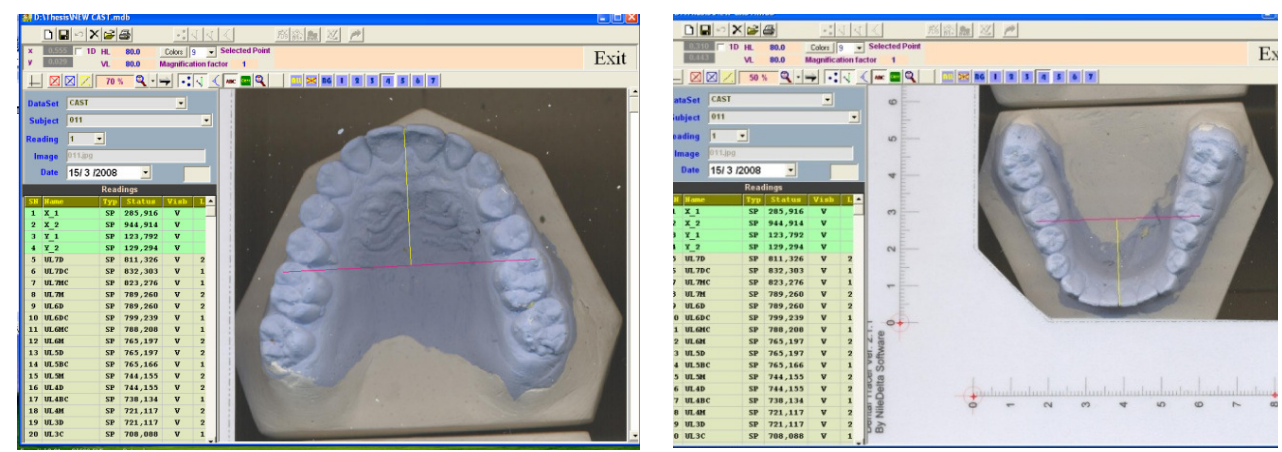

Fig 4: Maxillary and mandibular posterior arch lengths

\section{3- Total arch length:}

This was calculated by the measuring the distance between the inter-incisal point to the mid-distance of inter-second molar width. (Fig 5)

\section{4- Arch perimeter:}

This was calculated by the measuring the distance between the mesiobuccal cusp tip of the first molar on one side passing through cusps tips and incisal edges to its corresponding on the other side. (Fig 6) 


\section{5- Mesiodistal teeth width:}

This was calculated by the measuring the greatest mesiodistal measurement from the anatomic mesial contact point to the anatomic distal contact point of each tooth. (Fig 7)
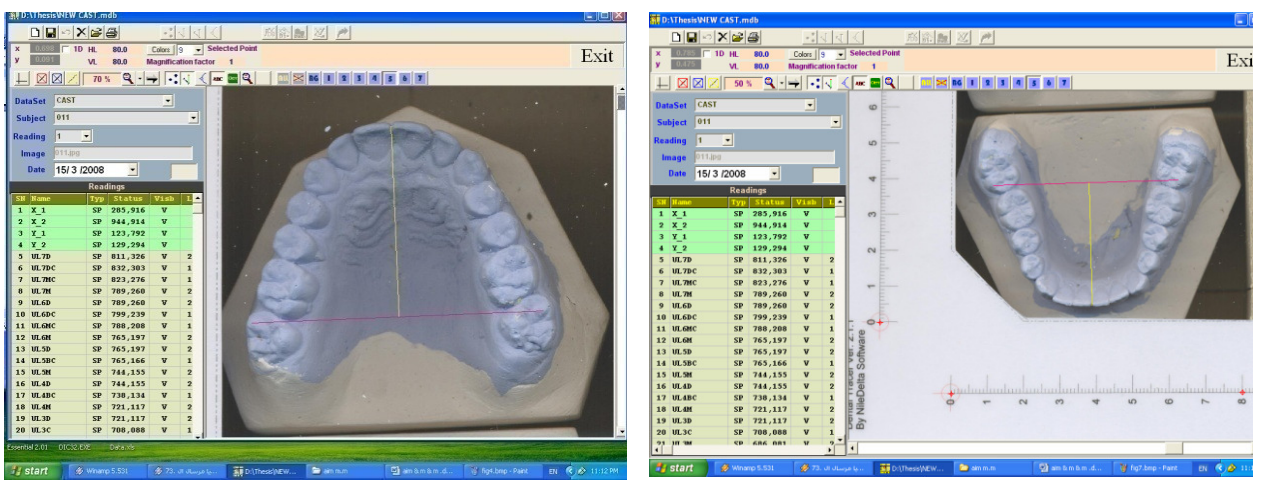

Fig 5: Maxillary and mandibular total arch lengths

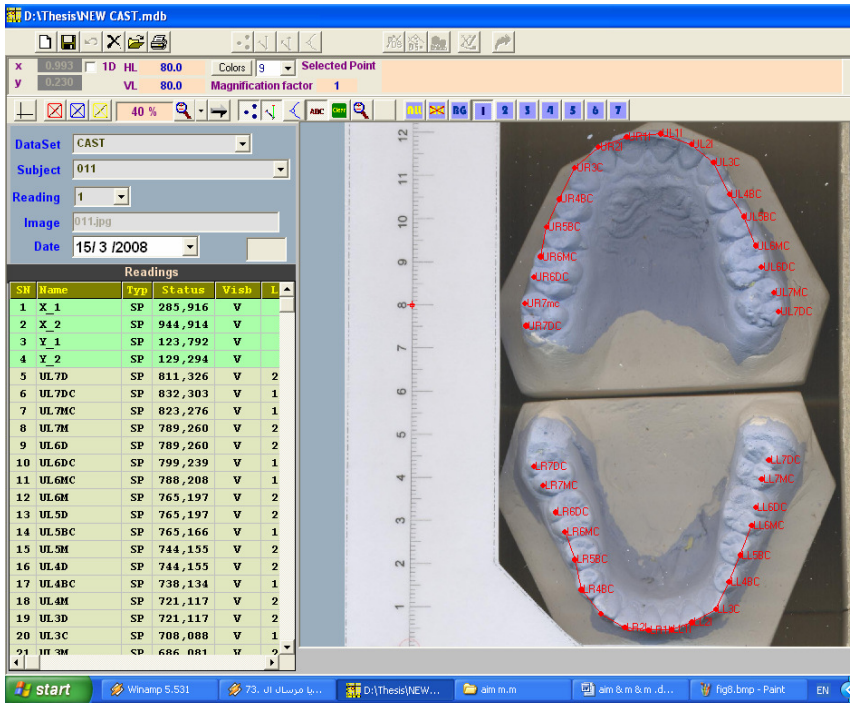

Fig 6: Arch perimeter 


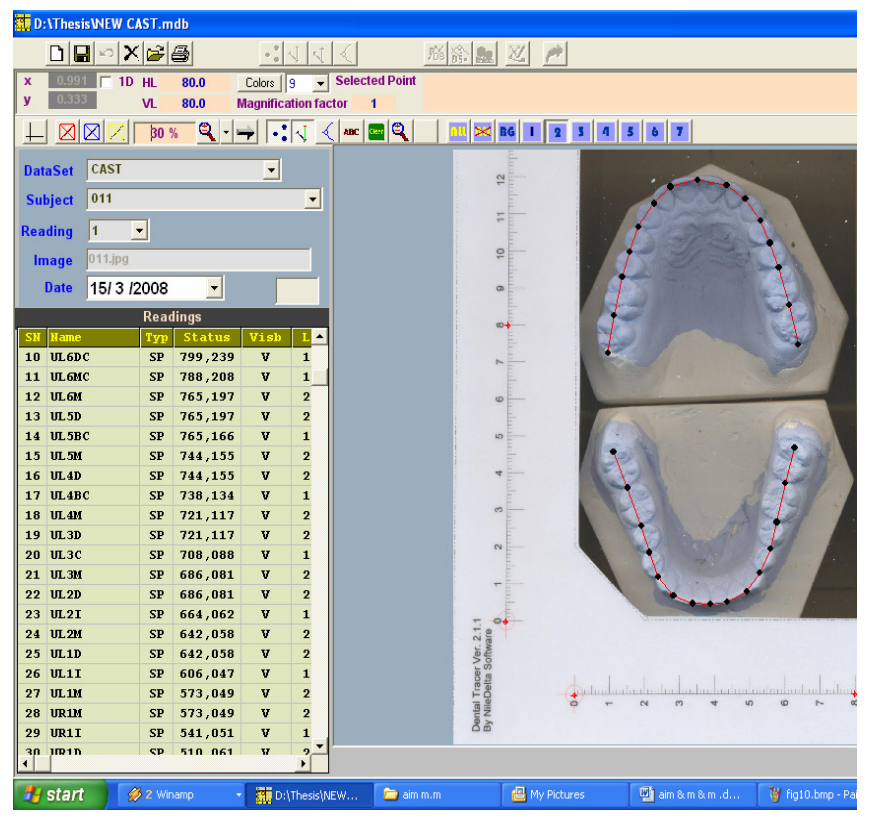

Fig 7: Mesiodistal teeth width

Concerning arch form, five independent ratios were calculated for each upper \& lower arch in order to characterize the different arch forms. These ratios were:

a- Anterior arch length / inter-canine width

b- Posterior arch length / inter-first molar width

c- Total arch length / inter-second molar width

d- Inter-canine width / inter-first molar width

e- Posterior arch length / total arch length

Means clustering method was used for classification of the arch forms.

\section{RESULTS}

Collected data was statistically analyzed with SPSS 15.0:

1- Descriptive statistics including mean, standard deviation and range were computed for each parameter. 
2- Paired t-test was used to compare between means. Pearson's correlation coefficient was used to determine significant correlations between the measurements.

3- K-means cluster analysis was used for classification of the arch forms.

4- Chi-square $\left(\mathrm{x}^{2}\right)$ test was used to compare between arch form distributions.

For maxillary arch 3 arch forms were distinguished; wide, pointed and square. The same forms represented the mandibular arch.

For maxillary arch: (Fig 8)

- Wide and pointed arch forms showed higher percentages than square arch form.

For the mandibular arch: (Fig 9)

- Wide arch forms showed the highest percentages.

\begin{tabular}{|c|c|c|}
\hline Form1: wide & Form 2: Pointed & Form 3: Square \\
\hline 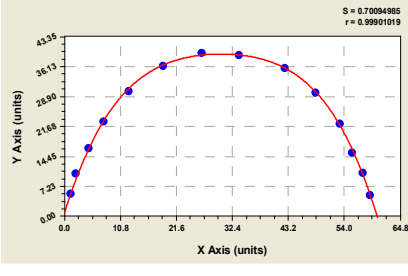 & 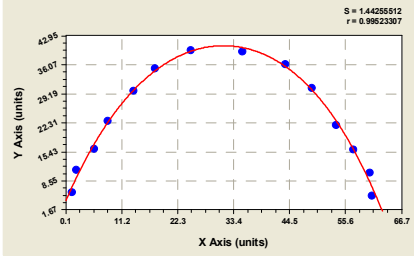 & (20, \\
\hline $\begin{array}{l}\text { 4th Degree Polynomial Fit: } \\
y=a+b x+c x 2+d x 3+e x 4\end{array}$ & $\begin{array}{l}\text { 4th Degree Polynomial Fit: } \\
y=a+b x+c x 2+d x 3+e x 4\end{array}$ & $\begin{array}{l}\text { 4th Degree Polynomial Fit: } \\
y=a+b x+c \times 2+d x 3+e x 4\end{array}$ \\
\hline Coefficient Data: & Coefficient Data: & Coefficient Data: \\
\hline $\mathrm{a}=1.012139$ & $a=3.5759679$ & $a=6.1831657$ \\
\hline$b=3.9879537$ & $b=2.7883248$ & $b=4.0992644$ \\
\hline$c=-0.16322276$ & $c=-0.072191712$ & $c=-0.18850915$ \\
\hline $\mathrm{d}=0.0032317331$ & $d=0.0008996527$ & $d=0.0041541205$ \\
\hline $\mathrm{e}=-2.6979031 \mathrm{e}-005$ & $\mathrm{e}=-7.4206181 \mathrm{e}-006$ & $\mathrm{e}=-3.7637149 \mathrm{e}-005$ \\
\hline
\end{tabular}




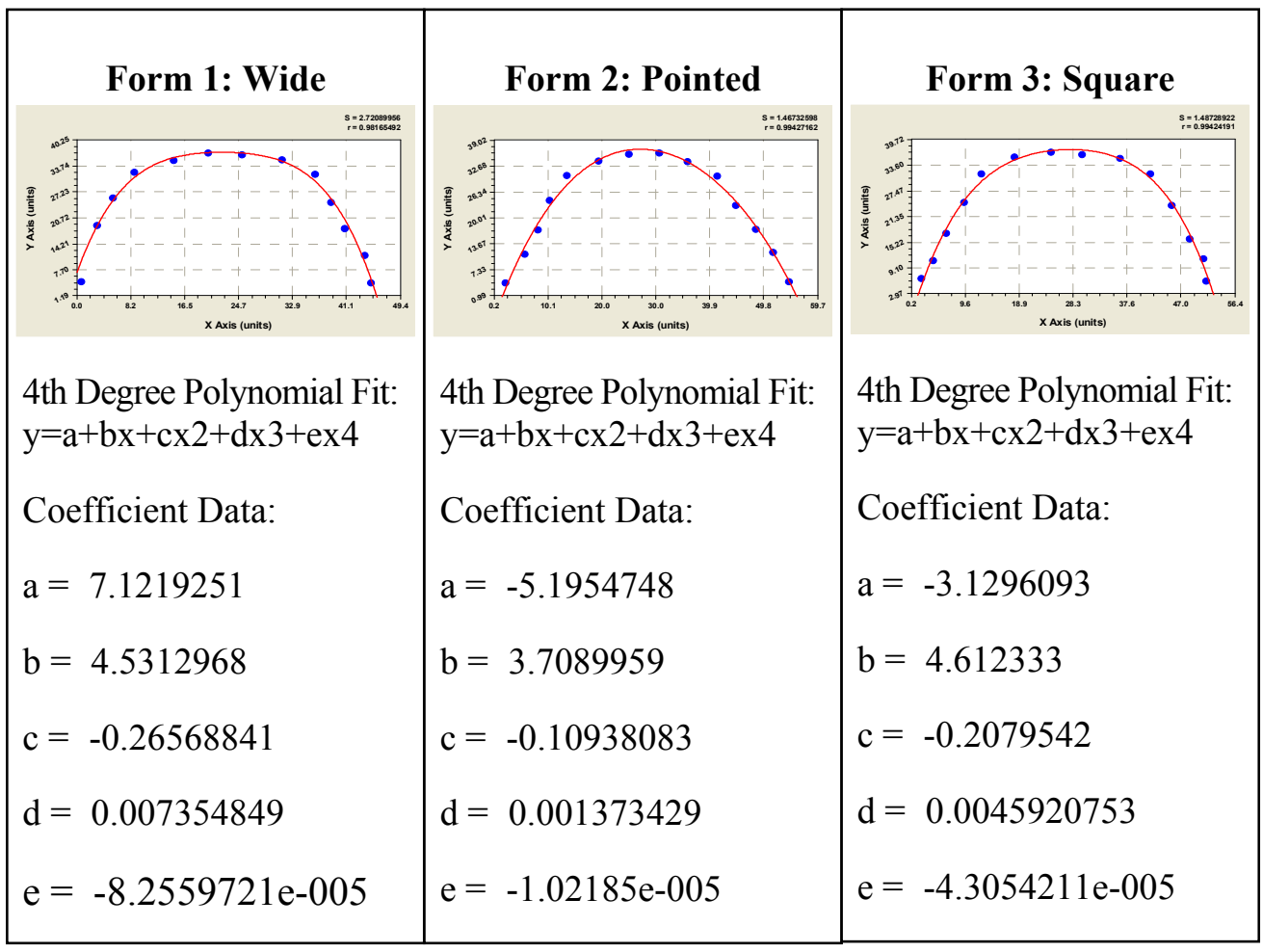

Fig 9: Mandibular arch forms

Table 1: The frequencies, percentages and results of chi-square test for the comparison between arch form distributions

\begin{tabular}{|c|c|c|c|c|c|c|c|}
\hline \multirow{2}{*}{ Arch } & \multicolumn{2}{|c|}{ Wide } & \multicolumn{2}{c|}{ Pointed } & \multicolumn{2}{c|}{ Square } & \multirow{2}{*}{ P-value } \\
\cline { 2 - 8 } & Frequency & $\%$ & Frequency & $\%$ & Frequency & $\%$ & \\
\hline Maxillary & 152 & 38 & 155 & 38.75 & 93 & 23.25 & $<0.001^{*}$ \\
\hline Mandibular & 166 & 41.5 & 119 & 29.75 & 115 & 28.75 & $0.002^{*}$ \\
\hline
\end{tabular}

*: Significant at $\mathrm{P} \leq 0.05$ 


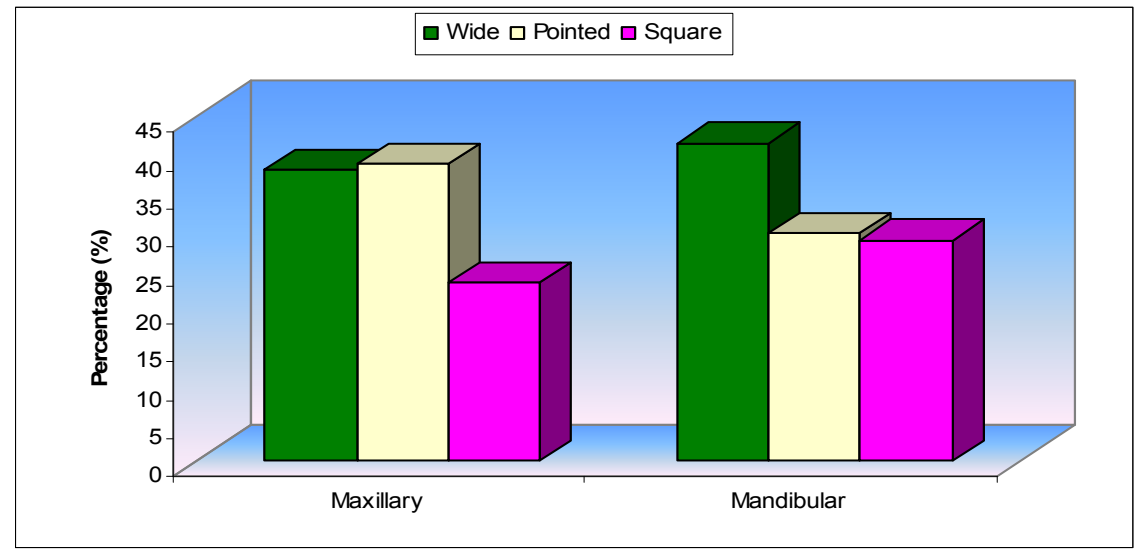

Fig 10: A bar chart showing distribution of maxillary and mandibular arch forms

\section{DISCUSSION}

Study and determination of criteria of different ethnic group is essential to promote accurate diagnosis and planning of orthodontic treatment. Dental arches of ethnic groups have certain characteristics that should not be taken as standards for other areas with different developmental and ecological foundations. Accordingly the aim of this study was to establish upper and lower arch forms for subjects from pure races in Upper Egypt.

The age selected was 14-16 years to assure the eruption of all permanent teeth. The study was restricted only for males to standardize all factors which might compromise the results. This concept is supported by many authors ${ }^{(7)}$ who claimed that tooth size differed according to sex.

In this study, a specially designed computer-aided occlusogram was used. This technique was used since other methods take images by special cameras or by photocopying machine then trace or digitize these images again which renders them sophisticated. ${ }^{(16,23)}$ In addition, as the number to get this occlusogram increases, the percentage of error will increase.

In this study, five reproducible fixed control points were selected. They were mid-point of the central and lateral incisors, the cusp tips of 
the canines, the buccal cusp tips of the first and second premolars, the mesiobuccal and distobuccal cusp tips of the first and second molars.

For accurate description of the arch form, individuals with functional permanent dentition and stable arch dimensions were selected. The inter-canine width as well as the anterior arch length accurately describe the arch form anteriorly (pointed or square). The inter-first molar width was selected since it also gave full picture about the width of the arch. The ratio between the inter-canine width and inter-first molar width distinguished whether narrow or wide arches.

The inter-second molar width was not taken into consideration. Moreover, it was not given great concern in previous investigations. The case was that most orthodontic appliances were dealing with the arch mesial to the second molar without incorporating it. In addition, almost all commercially produced ready formed wires tend to narrow or being unchangeable distal to the first permanent molar while the dental arch tends to be wider posteriorly. ${ }^{(6)}$

The anterior, posterior and total arch lengths were selected to complete the skeleton of the arch form. Five independent ratios: anterior arch length/inter-canine width, posterior arch length/inter-first molar width, total arch length/ inter-second molar width, inter-canine width/inter-first molar width and posterior arch length/ total arch length were selected to cluster the arch forms and to describe each form of the maxillary and mandibular arch. ${ }^{(6,15)}$

Three arch forms were distinguished: wide, pointed and square. Concerning the maxillary arch, wide and pointed arch forms showed higher percentage than square arch form. In the mandibular arch, wide arch form showed the highest percentage. Pointed and square arch forms showed lower percentage.

\section{CONCLUSION}

The idea of a single ideal arch form could not be substantiated in this sample of Upper Egypt school children. 
Egyptian

Orthodontic Journal

\section{REFERENCES}

1- Abdel Sayed FA: Tooth size among different types of malocclusion in a group of Egyptian adults. MSc thesis, Faculty of Oral and Dental Medicine, Cairo University, 1991.

2- Al-Khadra BH: Prediction of size of unerupted permanent teeth. Am J Orthod Dentofac Orthop; 1993, 104: 369-372.

3- Al Wosabi JO: Dental arch analysis of a group of Yemeni adults. MSc thesis, Faculty of Oral and Dental Medicine, Cairo University, 2002.

4- Aroujo E \& Souki M: Bolton anterior tooth size discrepancies among different malocclusion groups. Angle Orthod; 2003, 73: 307-13.

5- Bolton WA: Disharmony in tooth size and its relation to the analysis and treatment of malocclusion; 1958, Angle J Orthod, 28:113-130.

6- Borgan BE: Dental arch dimensions analysis among Jordanian school children. MSC thesis, Faculty of Oral and Dental Medicine, Cairo University, 2001.

7- Doris JM, Bernard BW \& Kuftinec MM: A biometric study of tooth size and dental crowding. Am J Orthod; 1981, 79: 326-336.

8- El Mangoury NH \& Mostafa YA: Orthodontic relapse in subjects with varying degrees of anteroposterior and vertical dysplasia. Am J Orthod; 1979, 75: 548-561.

9- Eid FH: Evaluation and application of Bolton analysis and Peck and Peck analysis on a sample of Egyptian population. MSc thesis, Faculty of Oral and Dental Medicine, Cairo University, 1984.

10-El Ajrami HA: Dental arch analysis for a group of Palestinian school children. MSc thesis, Faculty of Oral and Dental Medicine, Cairo University, 2002.

11-El Zahed HH: A study to determine the average tooth size and its relative relationship to arch width and length in a sample of Cairo school children. MSc thesis, Faculty of Oral and Dental Medicine, Cairo University, 1984. 
12-Essawy BI: Arch length analysis among a group of Upper Egyptian population. MSC thesis, Faculty of Dentistry, Minia University, 2008.

13-Fiorelli G \& Melsen B: 3-D occlusogram software. Am J Orthod Dentofac Orthop; 1999, 116: 363-368.

14-Hattab FN, Al Khateeb S \& Sultan I: Mesiodistal crown diameters of permanent teeth in Jordanians. Arch Oral Biol; 1996, 41: 641-645.

15-Kaddah MAF \& Ramadan MA: Mesiodistal crown dimension of the permanent dentition in a sample of Yemeni adolescence. Al-Azhar Dental J; 1979, 76: 95-99.

16-Marcotte MR: The use of the occlusogram in planning orthodontic treatment. Am J Orthod Dentofac Orthop; 1976, 69: 655-677.

17- Mutinelli S, Cozzani M, Manfrdi M \& Siciliani G: Dental arch analysis. Prog Orthod; 2004, 5: 200-11.

18-Nassef E \& Attia K:Evaluation of the best-fit commercially available customized memory wires arch form for the Egyptian adults group. Egyptian dental journal; 2003, 49: 895-904.

19- Othamn S \& Harradine: Tooth size discrepancies in an orthodontic population. Angle Orthod; 2007, 77: 668-74.

20- Peck S \& Peck H: crown dimensions and mandibular incisor alignment. Angle Orthod; 1972, 42:148-153.

21-Richardson ER \& Malhotra Sk: Mesiodistal crown dimension of the permanent dentition of American Negroes. Am J Orthod; 1975, 68:157-164.

22-Ross-Powell RE: A longitudinal study of arch size and arch form in African American children. Am J Orthod Dentofac Orthop; 2001, 119:130.

23- Yen C: Computer aided space analysis. J C Orthod; 1991, 25: 236-238. 